\title{
The Representation of Masculine Identity in Birell Egyptian Television Advertisement: A Semiotic Approach
}

\author{
Israa G. Suleiman \\ (Master) Degree - English Language Department \\ Faculty of Women -Ain Shams University- Egypt \\ israa.suleiman@hotmail.com \\ Prof. Wael Ismail Abdelbary \\ Professor of Sociology \\ Faculty of Women -Ain Shams University- Egypt
}

\begin{abstract}
The non-alcoholic beer Birell is specified in their advertisements' campaign to men. The campaign's slogan repeatedly in all their television advertisements says, "Man Up and Drink Birell," and they show men before and after they drink Birell to emphasize the strong effect it has on their manhood. This paper chooses one of their television advertisements to analyze the behavior of the male actor before and after he drinks Birell, since the before-behavior is doomed and frowned upon; however, the after-behavior is celebrated and encouraged as a strong macho. This paper aims at examining the represented masculine identity in "Birell at the Barbershop" Egyptian advertisement in the light of current scholarship on gender and masculinity. By presenting the concept of masculinity as defined by Joseph Prud'homme and the concept of gender performativity as defined by Judith Butler in relation to the portrayal of the masculine identity. Unfortunately, the masculine identity has been molded in a misrepresented way and stereotyped for the capital gain of powerful institutions-this results in manipulating the consumers' desires and motivating them to purchase the product. This paper attempts to reveal the representation of celebrated features of the macho man through the semiotics tools. Applying the semiotic tools of the signs of verbal, nonverbal, and character to the Egyptian television advertisement helps unveil the false representation allotted to masculinity and the dire consequences of such representation on the individual.
\end{abstract}


Keywords: Masculinity, Judith Butler, Joseph Prud'homme, Gender performativity, Advertising, Semiotics, Birell.

\section{Introduction}

The present paper explores the traditional masculine stereotypes portrayed in the Egyptian television advertisement entitled (Birell at the Barbershop, 2012). The study relies on the definition of masculinity by Joseph Prud'homme and the concept of gender performativity as discussed by Judith Butler in relation to the portrayal of masculine identity. Masculine identity has often been molded in TV advertisements in a misrepresented way and stereotyped for the capital gain of powerful institutions - thus manipulating consumers' desires to purchase specific products. This paper attempts to reveal the representation of the celebrated macho man through semiotic tools. The methodology of this paper applies the semiotic tools of the signs of verbal, nonverbal, and the character in an Egyptian television advertisement.

The analysis helps to unveil and checks if there is false representation allotted to masculinity. The researcher attempts to answer these questions: How does (Birell at the Barbershop) Egyptian Television advertisement represent the masculine identity? What is the Egyptian role model for men in this television advertisement? How does the dialogue in (Birell at the Barbershop) television advertisement serve in reflecting masculine identity? How do the nonverbal signs in (Birell) television advertisement help in reflecting masculine identity? How do the characters in (Birell) television advertisement aid in reflecting masculine identity? These questions are answered through first defining masculinity and gender performativity, then identifying relevant tools of semiotics. Secondly, the paper provides a narration of the television advertisement followed by the semiotic analysis.

The television advertisement under analysis is Birell, 2012; it markets a non-alcohol beer, and its duration is thirty-four seconds. This television advertisement is analyzed semiotically by focusing on the dialogue, the nonverbal signs, and the characters. This advertisement is chosen as it fits the theme that shows the representation of stereotypical features of masculine identity.

(Birell) starts with man 1 who enters the barbershop, speaks in a loud, confident and irritated voice, asking about the person whose red car is parked in 
front of the garage. Man 2, who is enormous, well-built, answers the question rudely with another question: "What is wrong, my son?" In the second scene, the two men stand confronting each other. Man 1 is still staring boldly at man 2, speaking in a confident tone now, a more authoritative voice; "Yes, there is something wrong! It is a garage! (a mustache is added to his face)" (00:06 00:8 my translation).

In the next scene, man 2 gets closer to man 1 as a threatening act, insinuating that he is ready to fight. A close-up shot focuses on man 2 challenging way of raising his eyebrow and staring at man 1 . The camera moves to man 1, still, close-up shot to focus on his face; he gets somehow scared from man 2's threatening behavior, especially as mentioned above that he has a bulk body. Thus, man 1 changes his voice into a softer tone and lower pitch, "With your permission, sir. Could you move it please?" (00:13 -00:16 my translation). The added mustache is taken off from his face. Then, man 2 playfully acts as if he is about to touch/punch man 1, but he does not, preaching his personal space as if to attack while doing a short whistle. Man 1 feels scared and takes a step backward, moving his hands in front of his chest by way of defending himself. Immediately, a female long braided wig is placed on man 1.

Then man 2 gives the keys to a boy telling him to move the car for him. The barber comes and says, "The steam is ready, big man" (00:21-00:22); while man 2 sits on the chair, prepared for the steam facial, a long curly wig is placed on his head as he says, "Hurry up" in a stern voice. While he is on the chair to have the facial steam, there is a close-up shot to show his back and him looking in the mirror at himself, then a long curly female wig is added to his head. When he is looking at himself in the mirror, the close-up shot signifies his interest in his looks as he is in the barbershop to make a skin routine.

Finally, the voice-over comments, "There is a thin line between manliness and a...a... a... Drink Birell! Cause anyone of us can fall anytime" (00:24 - 00:28 my translation). Man 1 is shown drinking Birell; consequently, a beard is placed over his face, and his chest is full of hair as he howls like a wolf, as shown in the below image (Image 1 Birell at the Barbershop). The voice-over ends with "Birell. Estargel [Man Up]" (00:32-00:34). 


\section{Masculinity: Objectification of Men}

In "Popular Culture and the Male Body: A New Challenge," Professor Joseph Prud'homme (2015) discusses the "commodification and sexualization of the male body" in media. He argues that this objectification of men is an undermined and seminal issue. When any gender is subject to objectification, they are treated or put in a weaker position since they are treated as objects. As Lindsay Wilson (2015)explains, "Objectification- the act of treating a person like an object rather than an agentive being, is often significantly gendered and, further, it is central to the process of gendering a person, and rendering them legible as human beings" (p. 1). Regarding men are objectified within the scope of masculinity, where they are expected to acquire a certain body image:

Body-image disorders follow the pattern set by the market's idealized forms. For women, this generally means becoming thin. Men, on the other hand, inordinately desire muscle mass and muscular tone, leading in turn to steroid abuse and the dangerous over-ingestion of unregulated muscle-building supplements. (Prud'homme, 2015, NP)

This is shown in the choice of actors in media who have a muscular tone, and their body image is emphasized and associated with their macho identity.

In addition, the represented gender identity of men is what Prud'homme elucidates as "the power to arouse the opposite sex-is creating serious but underappreciated consequences." Thus, men's identity becomes consolidated due to their ability to attract women, as explained by Prud'homme, which adds to the worth and value of their masculinity. Accordingly, masculinity rests on two aspects: the massive body and multiple relationships with women.

(Birell) advertisement demonstrates a self-objectification of the male identity. According to Calogero (2012) defines self-objectification as

Self-objectification is defined as the adoption of a third-person perspective on the self as opposed to a first-person perspective such that girls and women come to place greater value on how they look to others rather than on how they feel or what they can do. An objectified body is a malleable, measureable, and controllable body. By viewing and treating themselves as sexual objects, it is argued that girls and women act as their own first surveyors in anticipation of being evaluated by others. (p. 575)

Calogero (2012) explains self-objectification as when a person applies others' ideas upon himself; in this way, this person is self-objectifying himself:

Thus, the body becomes the site of reparative action and vigilant monitor-ing to manage the sexual objectification. When girls and women view 
themselves through this self-objectified lens, they take a peculiar stance on their own bodies that is fundamentally dis-ruptive to the self-body relationship. (p. 575)

Men's language becomes 'the site of reparative action and vigilant monitoring to manage sexual objectification.' When men evaluate themselves through this self-objectified lens, they modify their language and action to conform to the patriarchal society's constructed male identity. This leads to a stereotype of the male personality: rough voice and aggressive language, as this advertisement shows any sign of weakness is considered shameful as discussed in the analysis below. Becoming a man takes place through the consolidation of this masculine identity, which is objectified as seeing/evaluating themselves and other men through the societal idea of a 'man' as an example, the language of the bulky men in Birell advertisement, as he speaks to another man who is almost his age and addresses him as "my son" which reveals underestimation.

Women often look at their own bodies through men's lens; however, in this advertisement, men look at their bodies and evaluate themselves and others through the identity constructed for them by society. For instance, the ideal body standards for men depend on the body shape:

Because masculinity is believed to proceed from men's bodies, it is by and large presentational (Connell, 1995; Epstein, 1988; Fiske, 1987; Kimmel, 1996; Mead, 1967). The male body is a tool that men, on various levels of consciousness, manipulate in or- der to achieve a gendered identity. This is clearly illustrated in the way that society ranks men accord-ing to physical strength and athletic ability... In short, masculinity is not a matter of the mind, but of the body (Rohlinger, 2002, p. 262)

This quotation explains the dependent relation between gender identity and the standard body image required from men. The male gender identity is represented here through the muscular, tall, bulky man who is considered the epitome of masculinity by a visual effect of adding a mustache to his face to reinforce his masculine identity whenever he speaks in a rough voice, as explained in the analysis below.

Moreover, this advertisement proves the validity of Butler's theory on gender and performativity since becoming a woman or a man is via practicing their gender roles created by the patriarchal society, applied negatively since toxic masculinity is celebrated. For example, in (Birell) advertisement, men's aggressive fighting attitude, using their physical strength to exercise power over others, is encouraged strongly as shown, in the analysis below, by the voice- 
over who says in a confident tone, "There is a thin line between manliness and a...a... a... Drink Birell! Cause anyone of us can fall anytime" (00:24 - 00:28 my translation) then man 1 is shown drinking Birell and turning into a wild animal, a gorilla or a black wolf then howling in anger, after that the voice-over concludes determinedly, "Birell! BE A MAN!" (00:30 - 00:32 my translation). Furthermore, it is emphasized that becoming a woman is playing the role of the passive and vulnerable as in this advertisement, whenever he lacks selfconfidence and is hesitant and speaks in a lower voice, a female wig is added to him as a sign that he is acting similar to women.

\section{Judith Butler's Gender Identity: Body and Language}

In this section, the notion of gender identity will be tackled from the perspective of the feminist philosopher and gender theorist Judith Butler to demonstrate the gender stereotypes in (Birell) television advertisement. Butler (2011) argues:

Consider the further consequence that if gender is something that one becomes-but can never be-then gender is itself a kind of becoming or activity, and that gender ought not to be conceived as a noun or a substantial thing or a static cultural marker, but rather as an incessant and repeated action of some sort. If gender is not tied to sex, either causally or expressively, then gender is a kind of action that can potentially proliferate beyond the binary limits imposed by the apparent binary of sex. (p. 143)

She negates the societal concept of gender identity because it is predetermined and a natural consequence of one's biological sex. It is more complex than that, it is a performance of certain behaviors, dress, and discourse, and by doing so, one consolidates and acquires his/her gender.

\section{Body}

Butler also explains that gender is constructed through language, society, and corporeality. 'Gender is a 'corporeal style,' an act (or a sequence of acts), a 'strategy' which has cultural survival as its end" (Butler, 1988, p. 58). Corporeality is the way the body is used to perform one's gender. It defines one's gender in various methods such as body movements, gestures and styles, choice of clothes, and colors.

The choice of clothes can speak out their gender; by wearing a dress or a suit, one performs her or his gender identity, respectively. The way one handles 
and dresses one's body is another method of performativity: women tend to use cosmetics to become more feminine, and men tend to show and accentuate their muscles. The body's movement and space one takes also accentuates one's gender. An example is the way of sitting, as feminine girls are expected to cross legs suggesting limited space, while macho men would take larger space by sitting with their legs wide open. As Butler (2011) elucidates, the concept of gender:

Ought not to be construed as a stable identity or locus of agency from which various acts follow; rather, gender is an identity tenuously constituted in time, instituted in an exterior space through a stylized repetition of acts. The effect of gender is produced through the stylization of the body and, hence, must be understood as the mundane way in which bodily gestures, movements, and styles of various kinds constitute the illusion of an abiding gendered self. (Original Italics p. 179)

These gender stereotypes are what Butler explains as gender performativity. Thus, the semiotic analysis studies the television advertisement's characters to pinpoint their gender performativity- the acts/behaviors, costumes, diction, and voice related to each gender. Therefore, in this television advertisement, men and women are represented in a certain way to adjust to the historical and social forms created for them. Butler (2011) opposes the preexisting notions of gender roles in society. She claims:

$\{\mathrm{T}\}$ he very notions of an essential sex and a true or abiding masculinity or femininity are also constituted as part of the strategy that conceals gender's performative character and the performative possibilities for proliferating gender configurations outside the restricting frames of masculinist domination and compulsory heterosexuality. (p. 180)

They attempt to perform or carry out such behaviors to prove their gender even if, in some cases, these actions might be sexist or disrespectful to others. This demonstrates the societal pressure, adverse influence, and the suffocation of quickly adopting a certain mold of the gender stereotypes.

Butler (2011) explains Simone De Beauvoir's viewpoint that "the female body ought to be the situation and instrumentality of women's freedom, not a defining and limiting essence" (p. 16). So, here the body is an extensive opportunity for either expression of revolt and freedom or oppression. The body is the medium where one can apply the expectations of society to avoid being doomed. These expectations support or reject gender identities. In Butler's article "Performative Acts and Gender Constitution: An Essay in 
Phenomenology and Feminist Theory," she summarizes Simone de Beauvoir's and Merleau-Ponty's views on the body as follows, "the body is a historical situation, as Beauvoir has claimed, and is a manner of doing, dramatizing, and reproducing a historical situation. (Butler p. 521). First, the body as "a historical idea" rather than "a natural species" (Butler p. 520) is vital as the idea of a historical being means that it is limited to a preexisting version that would be difficult to alter.

Second, Butler (2011) points out that the body's performativity has "a manner of doing, dramatizing" (p. 521) and stresses that it is not a natural consequence; this deconstructs the traditional cultural ideas of stereotyping for women and men in the television advertisement. Third, "reproducing a historical situation" occurs clearly in the television advertisement where these stereotypes of gender identities and gender roles are consistently repeated until they are entirely internalized.

They oppose the culturally constructed genders, the frames, and societal expectations of gender and advocate for a time. In this way, they give a space of gender freedom of expression that supposedly should not be punished by society, since according to them, then society will have no preexisting model of gender to compare with the expressive performative gender. As Butler (2011) illustrates:

When the constructed status of gender is theorized as radically independent of sex, gender itself becomes a free-floating artifice, with the consequence that man and masculine might just as easily signify a female body as a male one, and woman and feminine a male body as easily as a female one. (p. 10)

As explained above, the identity is predetermined, and certain behaviors are expected to be performed or acted out to become this identity. To illustrate, one will get attracted to "'compulsory heterosexuality' - the dominant order in which men and women are required or even forced to be heterosexual (Adrienne Rich qtd. in Salih 49)", even the clothes, the body language, the tone of voice, and choice of words - all are destined and certain. For example, this occurs in this television advertisement as for men to be perceived as cool or macho, and they need to dress in a certain way, use tough, sometimes aggressive tone of voice and coarse language. The advertisement thus proves what Butler (2011) claims, "the notion that gender "not biology, but culture, becomes destiny" (Butler p. 12). 
People act this constructed gender throughout their life. Therefore, the television advertisements represent and regenerate constructed gender identities, which, according to Butler, are repetitively produced and are not natural facts. Therefore, Butler refutes the idea of gender since she breaks it down into repeated various acts that became universal, valid, and unquestionable by time. As Butler (1988) explains 'Because there is neither an 'essence' that gender expresses or externalizes nor an objective ideal to which gender aspires; because gender is not a fact, the various acts of gender creates the idea of gender, and without those acts, there would be no gender at all" (p. 522). The ramification of the forced notions of gender identities is grave since they lack acceptance to one another, authenticity to be oneself, creativity or expression to dare to be different. Moreover, it leads to several sensations of anxiety, nervousness, and alienation that one fails one's own gender and loses society's acceptance and respect. The following quotation expresses her attitude towards such a delusional mirage that became a dogma that it cannot be shaken.

Gender is, thus, a construction that regularly conceals its genesis. The tacit collective agreement to perform, produce, and sustain discrete and polar genders as cultural fictions is obscured by the credibility of its own production. The authors of gender become entranced by their own fictions whereby the construction compels one's belief in its necessity and naturalness. The historical possibilities materialized through various corporeal styles are nothing other than those punitively regulated cultural fictions that are alternately embodied and disguised under duress. (Butler, 1988, p. 522)

Butler notes that what shows the characteristics of gender identity is watching a drag. A drag stresses oppositions and subtly makes a distinctive line between what is feminine and what is masculine. This is the first step of understanding the identity by identification of the feminine and masculine attributes, then attempting to understand the link between the attribute and the gender, especially that " $\{\mathrm{i}\} \mathrm{t}$ is the quintessential expression of personal agency in a context of late MODERNITY, a context in which naturalistic, biological, or ESSENTIALIST conceptions of the subject and of gender and sexual identity are no longer operative" (Castle, 2009, p. 105). For instance, lowering one's voice and apologizing should not be linked to femininity as presented in (Birell) television advertisement; decent, polite manners should not be associated with one gender. The contrary is applied to this television advertisement, as some characteristics, behaviors, and manners are divided between men and women. 
Therefore, this will be highlighted in the case study of (Birell) television advertisement.

\section{Language}

Language plays a crucial role in determining gender, as Salih points (2002) in Judith Butler:

A 'masculine' man or a 'feminine' woman. Gender identities are constructed and constituted by language, which means that there is no gender identity that precedes language. If you like, it is not that an identity 'does' discourse or language, but the other way around-language and discourse 'do' gender. (p. 56)

(Birell) television advertisement demonstrates the contrasting paradigm between gender identities by choosing words and tones of voice to perform femininity or masculinity. For example, in Birell in Barbershop the quarrel between the two men occurs as one of them parked his car in front of the garage. Thus, the other man enters the barbershop to fight with the man who parked his car in front of the garage. The advertisement shows that the man loses his power and becomes feminine or masculine by adding either a mustache or a long female wig as a humorous effect (the advertisement's whole narration and analysis are below).

So masculinity and femininity are manifested via two points: (1) the dialogue; by saying, "If you do not mind. Could you move it?" in a lower voice than when he first spoke confidently in a high voice. (2) Costume; emphasizing his weakness by relating him to women by adding a two-long-braided wig on his head. When the man uses polite language, saying "Please" or "Could you," he is consequently considered a female, which is why a long hair wig is placed on his head. However, when he uses an aggressive, loud tone in a commanding manner, he is considered a macho tough man; therefore, a mustache is added to him as a masculine sign.

Butler's theory does not exclude men since patriarchy has a serious effect on men as well "The restricting frames of masculinist domination and compulsory heterosexuality" (2011, p.180); their identity is shaped and confined as the opposite to women's identity, since "the 'antifemininity' component of masculinity is perhaps the single dominant and universal characteristic" (Kimmel, 2007, p. 2). When most of the advertisements about home-related products are addressed to women, subliminally, it becomes the woman's natural role, which creates the problem. As "Nancy Chodorow argues that the structural 
arrangements by which women are primarily responsible for raising children create unconscious, internalized desires in both boys and girls that reproduce male dominance and female mothering" (Kimmel, 2007, p. 2). Thus, men believe that it is not their duty, it is a woman's issue, and sometimes when a man tries to help in the household responsibilities by cooking or cleaning, he is advised/told not to do so. By detaching himself from cleaning and cooking, a man is defending his masculine identity. In this way, his role is constructed and reconstructed as well. Here the choice of words and the way of utterance are predetermined too for one's gender.

\section{Semiotics}

The researcher uses three semiotics tools: the signs of verbal, nonverbal, and characters, to highlight the representation of constructed gender identities in (Birell) television advertisement. Anthony J. Cortese explains in Provocateur Images of Women and Minorities in Advertising (2008) that "(a) semiotics of advertising as social life --- deconstructing, decoding, and deciphering that which is manifest or on the surface. Ad deconstruction is the analysis of advertising in such a way as to reinterpret implied meanings as symbolic rituals of postmodern societies" (p. 1). These pictures and words that influence people contain a number of signs. Therefore, the semiotic approach helps to decipher the verbal and nonverbal signs in the advertisement.

The first semiotic tool is the dialogue, which exposes the immanent/absorbed patriarchal ideologies. Sometimes the patriarchal notions are addressed through the dialogue on a subliminal/hidden level. The dialogue is significant in representing the identity of men as when they use words such as "sorry", "please", "excuse me?" or "could you" they are belittled and compared to women by adding to their head a long-haired wig. When men in the same dialogue raise their voice and use imperatives and exclamations, they are given their masculine identity back by adding a mustache or chest hair to them as a sign of macho and stoic man. Therefore, the semiotic tools are utilized to decode the advertisement's language to understand the actors' power relations and their association with each gender.

The power relations in the dialogues determine two elements: (1) the dialogue and the language used to define and distinguish the constructed binary opposition of the genders.

From a semiotic perspective, television advertisements consist of language and image information (both verbal and nonverbal signs) and provide 
particularly effective environment for examining the ambiguous nature of abductive inferencing; skilled copywriters value elusiveness and incorporate the incomplete reasoning of abduction into their messages. (Langrehr qtd. Bulut, 2003, in p. 49)

Looking through the connotations, the choice of words associated with each gender and their lexical meaning groups as negative or positive. Especially if the character is portrayed as cool or strong, what type of words or style does the character use. For instance, if the character's dialogue includes imperative, it means s/he is in a powerful position and vice versa. Another significant part related to the dialogue is the voice. For instance, the range of pitches differs from one gender to another, as Kress et al. (2001) argue:

Men use the higher regions of their pitch range to dominate and assert only the very highest voices, e.g. counter tenor, can become ambiguous in gender terms. In either case the dominant norms of the public, assertive 'masculine' voice will be at odds with the dominant norms of the private, intimate ('feminine') voice. (p. 83- 84)

(2) Subsequently, gender identity is performed through language via word choice and tone of voice. So each gender is expected to use language in the distinctive predetermined way, thus as demonstrated in the television advertisements if one flouts the latter, then they are condemned as failing to fit their gender and are shamed in the advertisement. The idea here is flouting the chosen or the expected language for one's gender is condemnation and failure to perform one's gender, which results in a social stigma and vice versa.

Kress et al. elucidate the importance of the interpretation of the content to disclose the ideology behind the advertisement, "in this they perform a broadly pedagogic function - telling readers what values and practices to adopt, how to think of themselves, who and how to be" (Kress et al., 2001, p. 38). Thus, the interpretation of the discourse is a vital semiotic mode in understanding the constructed genders. This would happen through focusing on the voices in the dialogues, such as tension and pitch since "the loud voice claims most territory, whereas the soft voice excludes all but a few others, and is therefore associated with intimacy, confidentiality and so on" (Kress et al., 2001, p. 83).

The second semiotic tool utilized in this study is the characters/actors as signs that give a particular meaning, as explained:

A semiotic approach to character (whether in the drama, novel, film, etc.) should begin, not by deciding the status of the object a priori, but by considering it in the first instance as an empty 'sign', or 'as a sort of articulated morpheme, 
a migratory morpheme manifested by a discontinuous signifier (a certain number of distinctive features) which points to a discontinuous signified (the "meaning" and "value" of the character). (Elam, 2005, p. 119)

Studying the television advertisement's characters as signs displays the meaning or value of it. As Elam explains the character is studies as a sign that should be decoded because it carries a certain meaning and value. Sometimes the actor in the advertisement represents certain stereotypes. For instance, the type of character is considered a masculine/real man, and the type of character is considered a powerless/vulnerable/less man. Hence, every character in the television advertisement has a certain meaningful role that carries a certain ideology or reflects society's ideology behind it.

As for the third semiotic tool, which is the nonverbal, Tadeusz Kowzan's classification of the sign-systems of theatre by the actor's auditive and visual signs such as word, tone, gesture, movement, make-up, hair-style and costume, and outside the actor's auditive and visual signs, for example, properties, settings and lightings, and pieces of music or sound effects (p. 73). For instance, the nonverbal signs are even more powerful than the dialogue as they expose the desires, feelings, and sometimes the unconscious of the characters. The nonverbal reveals the body language of the powerful masculine man versus the body language of a man who is represented as unmanly or cowardly.

\section{Television Advertisement: (Birell at the Barbershop)}

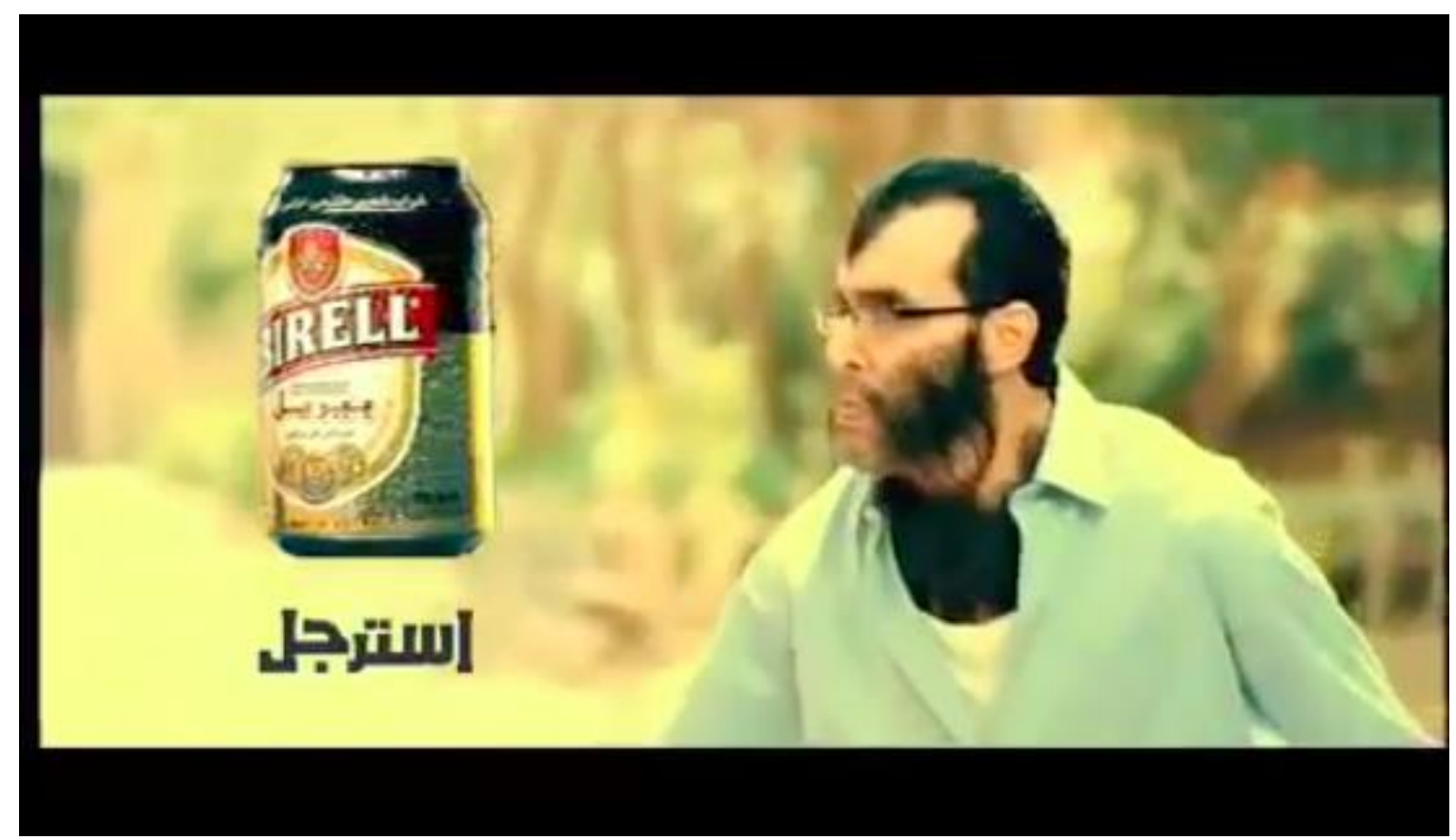




\section{Image 1 Birell at the Barbershop.}

\section{Food/Beverage and Identity}

This television advertisement perpetuates masculine identity through advocating for a certain drink, language, and body for men. It is specified this non-alcoholic beer for men with no logical reason. Furthermore, Judith Butler's concept of gender as a performance act resonates with Julie M. Parsons's concept of doing food, and this occurs in this advertisement, which asks men to drink this beverage to do their gender. As Julie elucidates in her book Gender, Class and Food (2016):

It is notable therefore that foodways (like gender and class) work within three interconnecting domains: (1) on an 'individual' level, through socialization, internalization, identity work and the construction of the self; (2) through interactional 'cultural' expectations and 'othering' of practices; and (3) via 'institutions that control access to resources, as well as ideologies and discourses (Risman 2004). Thus, performances of everyday foodways are validated, constrained, facilitated by reference to wider institutional contexts that may include gender (patriarchy), class (economics), culture (capital) and 'the' family (discourse). Accordingly, everyday foodways inculcate a cultural habitus through the repetition, reproduction and reinforcement of values and tastes. (NP)

The irrational link between the drink and men feeds the established binary opposition between femininity and masculinity. As Bourdieu (1986) explains that the manner of presenting, serving and eating food, or everyday foodways fulfills the social function of legitimatizing social difference (p. 1). To be feminine, one has to avoid the other -the masculinity- meaning to avoid all the behaviors, tones, clothes, and even beverages and food associated with it. Interestingly and oddly enough, it seems that gendering food is enormously influential and successful in business since Birell, a renowned and lucrative company, continued in creating similar advertisements that carry the same ideas of sexism and chauvinism for many years afterward.

Judith Williamson, in her book Decoding Advertisements Ideology and Meaning in Advertising (1978), compares this linkage, between the product and feelings, to T.S Eliot's objective correlative:

T.S. Eliot describes this 'linking' or correlating aspect of art, as an 'objective correlative': 'The only way of expressing emotion in the form of art is by finding an 'objective correlative': in other words, a set of objects, a 
situation, a chain of events, which shall be the formula of that particular emotion; such that when the external facts, which must terminate in sensory experience, are given, the emotion is immediately evoked. (p. 30)

The problem here is specifying Birell to men and associating aggressive, rough, rude, or impolite manners with being macho. Birell beverage has a number of functions: (1) it engenders a currency for a muscular personality, and (2) it confines and molds men in fixed boundaries (3) it creates a shallow irrational binary opposition between the sexes. For example, strength and power are linked to males. On the other hand, vulnerability and politeness are related to females. These are characteristic traits, so being decent, kind, vulnerable, docile, confident, or strong varies from one person to another regardless of gender; it is not a natural consequence of one's biological sex.

\section{Clothes}

As Kowzan, Tadeusz explains in The Sign in the Theater: An Introduction to the Semiology of the Art of the Spectacle, that there is thirteen sign system to deciphered about the actor to give meaning to his performance, clothes are in his classification number eight under actor's external appearance category that includes clothes, make-up, and hairstyle. Thus, Clothes are signs to be decoded; it gives information on the characters' backgrounds. As LeedsHurwitz (1993) explains, "we use clothing as a vehicle to convey identity; it 'establishes what and where the person is in social terms.... when one has identity, he is situated - that is, cast in the shape of a social object by the acknowledgment of his participation or membership in social relations'" (p. 113). So clothes can be decoded to inform the readers sometimes about the characters' social context. For instance, Man 1 is slim, wears semi-formal clothes: long sleeves shirt, belt, formal pants, and eyeglass. The formal clothes and glasses give an attitude that he is a middle-class working man. Man 2 is wearing a heavy silver necklace, jeans, and a short-sleeved rolled-up shirt. The heavy necklace and the way his short-sleeved shirt are rolled up imply that he is from a lower/labor class.

The added wigs and mustaches are considered accessories; therefore, they are discussed under clothes. The intended subtle humorous effect is the addition of either mustaches or female long wigs to these men, depending on the context. If they are tough, rude, or aggressive, they are considered rugged and masculine- consequently, a mustache is added. If they speak in a well-mannered 
civilized way, it is considered a weak feminine behavior, so a long female wig is added to the man. Therefore, when man 1 answers in a rough, strong voice, the mustache is added to his face as a sign of power. Alternatively, when Man 1 feels scared and takes a step backward, moving his hands in front of his chest in the way of defending himself. The advertisement immediately places a female long braided wig on man 1's head, signaling femininity and helplessness.

\section{Body Language}

Butler argues that people use their bodies in a specific manner to show their identities: whether femininity or masculinity, since society draws certain acts to each gender identity. Salih (2002) elucidates Butler's notion:

Butler declares that 'all gender is, by definition, unnatural' before she proceeds to unprise sex and gender from what many would assume to be their inevitable connection to each other (SG: 35). Butler departs from the common assumption that sex, gender and sexuality exist in relation to each other, so that if, for example, one is biologically female, one is expected to display 'feminine' traits and (in a heteronormative world, i.e. a world in which heterosexuality is deemed to be the norm) to desire men. Instead Butler claims that gender is 'unnatural', so that there is no necessary relationship between one's body and one's gen-der. In that case, it will be possible to have a designated 'female' body and not to display traits generally considered 'feminine': in other words, one may be a 'masculine' female or a 'feminine' male. (p. 46)

Butler attempts to break the binary opposition between sexes and femininity/masculinity. By saying these are mere acts to display the identity constructed by society to avoid harmful societal reactions. As shown in the above-mentioned quotation, she continues to break the binary opposition by saying one could be a 'masculine female' or vice versa. In this advertisement, "Man up" says the voice-over, advising men not to become a 'feminine male'.

It is "unnatural" to link politeness to vulnerability and to link and specify vulnerability to only one gender -women by doing so, men are forced to behave impolitely and vulgarly in order to maintain their masculine identity; accordingly, in this advertisement, by winning a mustache when Man 1's body language indicates confidence -as while speaking, he is puffing out his chest, standing up straight back with shoulders back. Then, man 2 playfully acts as if he is about to touch/punch man 1, but he does not, preaching his personal space as if to attack while doing a short whistle. This act demonstrates his show-off of power over man 1 . 
This politeness strategy gives the impression that being strong is celebrated as a muscular act; this is demonstrated by adding a mustache or a hairy chest to the male actor, which is displayed as a reward. Moreover, the advertisement suggests that one has to show off one's muscles and be ready to fight in order to become a tough man. Otherwise, he is stigmatized and undermined into being a woman, which is offensive since it is associated with negative connotations such as fear, insecurity, and weakness. The advertisement negates the notion and possibility that men are soft, well-mannered, civil, or decent. It is important that, as Butler advocates, they entertain their rights to be and act the way they desire and should not be scandalized, offended, and considered less of men or insulted by comparing them to women -which is another catastrophe as if being a woman equals a helpless, passive and meek being.

Man 1's behavior changes two times in this advertisement. In the beginning, his body language and voice convey confidence, and then he loses both of them as he is threatened by man 2 . At the end of the advertisement, he gains his confidence back, and it is reflected in his body language and voice when he drinks Birell and becomes an angry howling wolf. Man 2 is overconfident and self-assured throughout the advertisement; this is shown in his constant loud and aggressive tone of voice and body language. Man 2 answers the question in a rude way: raising his eyebrow, which is a sign of contempt or rejection as well as dominance, standing up, swagger-walking towards man 1, and waving his hand, which is a gesture that carries signs of rudeness and indecency, asking, "What is wrong my son?". However, man 2 is stripped away from his masculinity, too, as the mustache is removed and replaced by a female hair wig due to having a steam facial since it suggests that skin-care is a feminine act. The advertisement's humor subtly reflects the binary opposition between what is considered feminine or masculine.

\section{Dialogue}

Another semiotic tool that is significant in this advertisement is dialogue. The dialogue between the two illustrates the positions of power. (1) When the barber calls him "big man", it is mentioned to consolidate and highlight his manhood and macho. Simultaneously, it is an ironic call since when the barber calls him so, soon afterward, he steams his face, which is ridiculed in the advertisement by adding a female curly wig to his head. (2) When the voiceover at the end says, "There is a thin line between manliness and a...a.... a... 
Drink Birell! Cause anyone of us can fall anytime" (00:24 - 28), gives a threatening tone and toys with the emotions of insecurity that one can be feminine which is a disastrous act for the majority of men. Then it provides a piece of advice in an imperative voice, which is to drink the beverage. So the voice-over concludes by the suggestion that becoming a man could happen by drinking Berill.

Another incident of dialogue that shows aggressive or powerful acts in relation to masculinity is when man 2 answers man 1 about "Who parked in front of the garage?" by responding, "What is wrong, my son?" In Arabic, calling another man "my son," especially in this context where they are almost the same age, is a socially undermining way as man 2 is belittling man 1 as though he is a boy and not a grown-up man. The way he communicates in the rest of the advertisement confirms that he is a mob who is ready to fight without a valid reason.

\section{Character as a sign}

Man 2's character is a semiotic sign of the ideal masculine man. Until he makes an action, taking care of his skin, this feminizes him and dooms him. The action is when they are in the barbershop, he goes to sit in front of the mirror, and the barber says, "The steam is ready big man," he sits while having a very aggressive look, still raising his eyebrow asking the barber in an authoritarian manner to "hurry up." Thus, a female wig is added to him as a sign of losing his masculine identity. The character is portrayed as masculine through some elements: being called "big man," having a bulk body, harsh voice, aggressive look, overconfident body language and tone of speaking, and ready-to-fight attitude. This results in disparaging men and women when: (1) by stripping men's identities -caring for certain qualities and (2) using women as insults.

\section{Masculinity}

Drew Bummer published an article about the Birell campaign entitled, "Birell ad draws criticism for 'encouraging' sexual harassment". She argued that "Birell's advertisement campaign has raised a storm on social media for telling its consumers how to 'be a man,' which critics say encourages objectifying women and male chauvinistic behavior". This advertisement puts stress and burden on men, urging them to be strong and tough in order to be appreciated and accepted in society as real men. 'Birell's 'be a man' ads, 
encourage users to drink their product to make themselves more masculine" (Brammer). So, according to this advertisement, being polite or tender will cause problems.

As Michael Kimmel, a professor in gender studies, elucidates:

I think, there is a model about being a real man in America, I think sometimes that model is more of a stoic, hard, tough, etc. my friend Joe Worman who used to be a professional football player, he says that he remembers his father just saying to him 'be a man, man up, toughen up, do not be a girl,' think about all the times you heard that when you were little. So we learned very early that anything that associated with femininity not only dangerous but could be devastating to our identities to men. (Man Enough Episode 1 05:49 - 06:30)

When men take care of their skin, it is considered a feminine act as having clear good-looking skin would not add to their strength or is related to the macho stereotype. It is only essential to take care of their body's strength and fitness to have well-built bodies that help fight. This is what Bourdieu talked about regarding the bodies being celebrated since they provide strength. As Bourdieu writes, "The way people treat their bodies reveals the deepest dispositions of the habitus" (p. 190). Bodies express the ideology of society; they are located in. Thomas et al. illustrate Bourdieu's example of bodies in relation to social classes preference:

Whereas weightlifting and heavy bodies are part of the habitus of the working-class male, mountaineering and tennis are more closely associated with the dispositions of the educated middle and upper classes...Because different types of bodies (strong and squat, lithe and athletic, or curvaceous and sexual) have different values in their respective fields, we can talk about the physical and symbolic capital of bodies. (p. 101)

Where the body becomes the medium people invest in their internalized ideology of society. Here, man 2 from a lower class celebrates his body and uses it to convey power, and in this advertisement portrayed as a man more than the middle-class man who has a slim body thus weaker.

"Many rights groups criticize gender-specific targeting in advertising, arguing it perpetuates stereotypes and fails to reflect the more modern realities of a less gender-defined 21st-century lifestyle" (Bummer). This division is socially constructed with unhealthy consequences. Many young men would be tempted to drink it merely to add to their masculine image; however, it is a repeated illusional notion and a false promise of buying a gender identity. 
Advertisements limit women and men; just because the beverage has a bitter taste which does not mean that it should be naturally related to men. It encourages people to believe that anything bitter, strong, or aggressive is related to men to the extent that some women might be shy to drink Berill in public to avoid being judged as less feminine.

Many Egyptian newspapers wrote articles condemning Birell's campaign as a social hazard. An online article named "The Beer Company Promoting Sexism and Sexual Harassment in Egypt" argues against it as it states, "It is unacceptable and infuriating that Birell has continuously released ads that promote sexism and gender discrimination...It is sexist. It is offensive. And more than anything, it is socially irresponsible. As a company with its popularity, promotion of social issues is not only a duty but an obligation" (Khairat).

\section{Voice-over}

Birell Company draws a natural, predetermined link between their beverage and the masculine identity through the imperative grammatical usage of the word "Man up!" uttered in a confident, loud tone by the voice-over, even though the link is irrelevant. As explained by Kress et al. (2001), a loud voice means confidence, "as a result vocal loudness is strongly related to power and domination" (p. 83); this 'power and domination' build a space for the audience to trust the confident voice-over.

The voice-over ends by saying that men need to drink Birell to maintain their masculinity. Simultaneously, the voice-over exclaimed, "There is a thin line between manliness and a...a.... a.... Drink Birell! Cause anyone of us can fall anytime" (00:24 - 00:28) then man 1 is shown drinking Birell and turning into a wild animal, a gorilla or a black wolf then howling in anger, after that the voice-over concludes determinedly, "Birell! BE A MAN!" (00:30 - 00:32). The transformation into a wild animal is a semiotic sign that refers to masculinity and strength. This is similar to the explication by Williamson (1978):

Images, ideas or feelings, then become attached to certain products, by being transferred from signs out of other systems (things or people with 'images') to the products, rather than originating in them. This intermediary object or person is bypassed in our perception; although it is what gives the product its meaning, we are supposed to see that meaning as already there, and we rarely notice that the correlating object and the product have no inherent similarity, but are only placed together (hence the significance of form). So a 
The Representation of Masculine Identity in Birell Egyptian Television Advertisement: Semiotic Approach

product and an imagelemotion become linked in our minds, while the process of this linking is unconscious. (Italics Mine p. 30)

As explained, a link is created between the product and a desire, feeling, or image of a celebrity that is irrelevant to the use-sign, in other words, to the function of the product. This often occurs in the advertisement for manipulation reasons and capital gain by advocating a certain idea, as in this advertisement by the voice-over's self-assured tone.

\section{Conclusion}

In conclusion, Butler explains the strong connection between body and gender since one has to act one's body in order to demonstrate their gender. The body becomes the instrument for this representation of gender identity. One has to conform to these cultural "corporeal style" or a "strategy" (Butler, 2011, p. 66); otherwise, they would be excluded from society. In this television advertisement, there is "a repetition, a copy of a copy (Butler, 2011, p. 66)," which occurs in the representation of gender identities. As exemplified for men are represented as macho and strong/aggressive. The character in (Birell) television advertisement is decoded as a sign which means that the man who flouts these predetermined, and who accordingly becomes doomed or undermined and turns into a laughingstock. Consequently, it confines men through setting certain expectations: of having a bulk body, readiness to fight attitude and usage of aggressive, harsh words which are not workable for everybody and man 2 is the epitome of all those characteristics.

The dialogue was used as a crucial factor to reflect the gender identities. This advertisement's language is sexist and derogatory, starting from the slogan, "/Birell estargel/ Birell man up". Also, using marketplace/vulgar language in the advertisement, such as undermining/insulting a grown man by calling him "son," is associated with power and masculinity. However, using polite language related to femininity and vulnerability as apologizing and hesitancy, which occurred in this advertisement by man 1 when he apologized and talked in a lower tone and his diction also conveyed hesitance. The dialogue conveyed the binary oppositions of gender as power and weak. Butler argues against this repeated history and tradition which assumes that all men are powerful and should carry a powerful attitude, on the other hand, women are the opposite, instead of dealing with them as human beings who have both attributes and some persons are more powerful than others regardless of their gender. It is noticeable that the gender representations that were celebrated as powerful held 
a destructive behavior. For instance, the masculinity presented was extremely toxic and harmful since the attributes linked to masculinity were aggression, rudeness, and aloofness and often usage of derogatory language and bullying.

Another catastrophic repercussion of the presence of patriarchy in this television advertisement is the manipulation of people's desires and insecurities for profit gain. This takes place as the ideologies of patriarchy and the capitalist institution are embedded in this society but come back disguised in new forms. This can be seen in the representation of gender identity, which is reinforced/imposed and reproduced through this television advertisement, as the macho aggressive man. This also serves the capitalist institution via selling the perfect home appliances, beverages or cosmetic products, and so forth, knowing that $\mathrm{s} /$ he will buy the commodities since they function as a metaphor for more love, acceptance, appreciation, and an assurance of his identity.

The nonverbal signs are the third important factor that helped understand the reflected construction of gender identities such as the body language, costumes, and accessories (wigs). Toxic masculinity was shown when the bulky man was using his body to show readiness for a fight. The analysis highlights the represented acts of femininity and masculinity; it is noticed that advertisement divides men's and women's identities into several behaviors. When one gender flouts his/her determined set of behaviors, he/she is doomed, as Butler elucidated. This takes place here by adding a female wig to man 2 . Since he is a man, he is shamed for taking care of his skin by having steam facial care. The analysis reveals that it is unfair and illogical to constrain, imprison and stereotype men with those accepted essential societal rules. 


\section{References:}

- Aston, E., \& Savona, G. (2002). Theatre as Sign System: A Semiotics of Texts and Performance. NY: Routledge.

- (Birell at the Barbershop). (2012). "'اعلان بريل الجديد - عندالحلاق."Youtube, uploaded by TheCafetube, 31 July 2012, https://youtu.be/vvqJdYgx-Pg.

- Bourdieu, P. (1996). Vilhelm Aubert memorial lecture: Physical Space, Social Space and Habitus. Oslo: Department of Sociology, University of Oslo \& Institute for Social Research,.

- ---.(1986). The Forms of Capital. Edited by John G. Richardson. Handbook of Theory and Research for the Sociology of Education. New York: Greenwood. 46-58.

- Butler, J. (1988) Performative Acts and Gender Constitution: An Essay in Phenomenology and Feminist Theory. Theatre Journal, vol. 40, no. 4, 1988, pp. 519-531. The John Hopkins UP, http://www.jstor.org/stable/3207893

- ---. (2011). Gender Trouble: Feminism and the Subversion of Identity. New York: Routledge.

- Brammer, D. (2020). Birell ad draws criticism for 'encouraging' sexual harassment. Egypt Independent, 2015, https://egyptindependent.com/birell-ad-draws- criticismencouraging-sexual-harassment/. Accessed Oct 2020.

- Castle, G. (2009). The Blackwell Guide to Literary Theory. Wiley.

- Calogero, R. M. (2012). Objectification theory, self-objectification, and body image. In: Cash, Thomas, ed. Encyclopedia of Body Image and Human Appearance. 574-580. ISBN 9780123849250. Accessed Oct 2020.

- Cortese's, A. J. (2008) Provocateur Images of Women and Minorities in Advertising.United Kingdom: Rowman\& Littlefield.

- Davis, A. Y. et al., editors. (2005) Beyond The Frame Women of Color and Visual Representation. Palgrave Macmillan.

- Elam, Keir. (2005) The Semiotics of Theatre and Drama. NY: Routledge. 
- Khairat, Mohamed. (2015) The Beer Company Promoting Sexism and Sexual Harassment in Egypt. Egyptian Streets.

https://egyptianstreets.com/2015/03/27/the-beer-companypromoting- sexism-and-sexual-harassment-in-egypt/. Accessed Nov. 2019.

- Kress, G. R., et al. (2001) Multimodal Discourse: The Modes and Media of Contemporary Communication. Arnold.

- Kowzan, T. (1968). The Sign in the Theater: An Introduction To the Semiology of the Art of the Spectacle. Diogenes, 16(61), 52-80. https://doi.org/10.1177/039219216801606104

- Kimmel, M. (2007). Masculinity. International Encyclopedia of Social Sciences. Ed. William A. Darity Jr. $2^{\text {nd }}$ ed. Vol. 5. New York: Macmillian Reference USA.

- Langrehr, D. (2003). From a Semiotic Perspective: Inference Formation and the Critical Comprehension of Television Advertising. Reading Online, 6 (9), 1- 16.

- Leeds-Hurwitz, W. (1993). Semiotics and Communication: Signs, Code, Cultures. Routledge.

- M. Parsons, J. (2016). Gender, Class and Food. 2016, Springer.

- Prud'homme, J. (2015) Popular Culture and the Male Body: A New Challenge. Public Discourse The Journal of the Witherspoon Institue, July 21, 2015. https://www.thepublicdiscourse.com/2015/07/15310/. Accessed Sept. 2020.

- Rohlinger, D.A. (2002) Eroticizing Men: Cultural Influences on Advertising and Male Objectification. Sex Roles, 46, 2002, 61-74. https://doi.org/10.1023/A:1016575909173.

- Salih, S. (2007) On Judith butler and Performativity. Sexualities and Communication in Everyday Life. Mercilee M. Jenkins e.d. Sage Publications.

- Salih, S. (2002). Judith Butler. Routledge.

- Strinati, D. (2004). An Introduction to Theories of Popular Culture. Routledge. 
- TEDx Talks. (2014). The Dangerous Ways Ads See Women Jean Kilbourne. Online Video Clip.Youtube. Web.

- Wayfarer Studios. (2018) Man Enough Episode 1 - Why Don't Men Talk. YouTube, uploaded by Wayfarer Studios, https://www.youtube.com/watch?v=dVsbYas4tVo. Accessed 11 Nov. 2019

- Williamson, J. (1978). Decoding Advertisements. London.

- Wilson, L. A. (2015). Gender Performativity and Objectification. ScholarWorks@Georgiastateuniversity, Georgia State Undergraduate Research, Conference,

https://scholarworks.gsu.edu/cgi/viewcontent.cgi?article=1416\&co ntext=gsu rc. 


\title{
تصوير الهوية الذكورية في الإعلان التلفزيوني المصري بيريل: دراسة سيميائية \\ إسراء جمال الدين سليمان \\ باحث ماجيستير-قسم اللغة الإنجليزية وآدابئ سابها

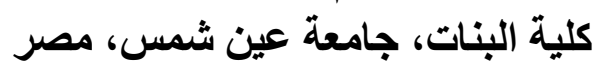 \\ israa.suleiman@hotmail.com
}

\author{
أ.د. وائل إسماعيل عبد الباري

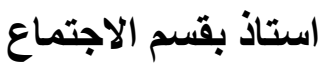 \\ كلية البنات جامعة عين شمس، مصر الاجترع \\ wailbarry@gmail.com
}

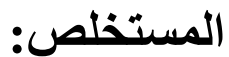

تتسبب الإعلانات دائما في حدوث ضجة في الاعلام و الصحافة و المجتمع، مما يجعلها مادة غنية

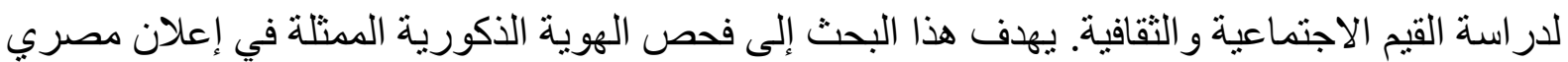
(بيريل في صالون الحلاقة) في ضوء الدر اسات الحالية حول الجندر و الذكورة ولتأثير ها الكبير في تكوين

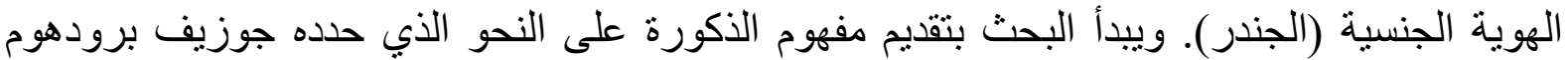

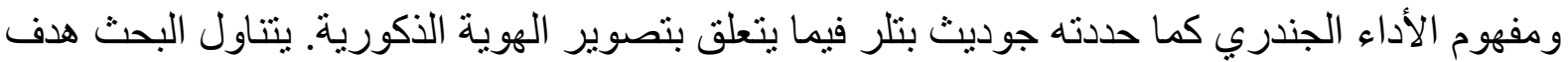
الإعلان وتأثيره القوي فيما يتعلق بالهوية الجنسية. وقد تم التوصل إلى أنه لسوء الحظة فئل فلد تم تشكيل الهوية الذكورية بطريقة مشو هة وصورة نمطية لتحقيق مكاسب رأسمالية للمؤسسات القوية؛ و هذا بدوره

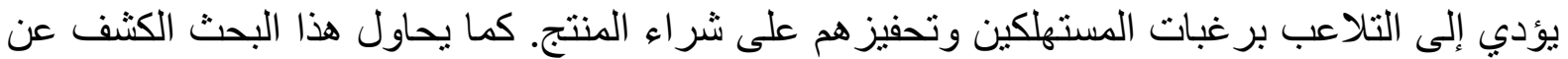
تمثيل الملامح الثهيرة للرجل مفتول العضلات من خلال تحليل الإعلان التلفزيوني المصري باستخديات الأدوات السيميائية مثل: الإشارات اللفظية و غير اللفظية و الثخصية. ويساعد التحليل في كثف الثف النقاب

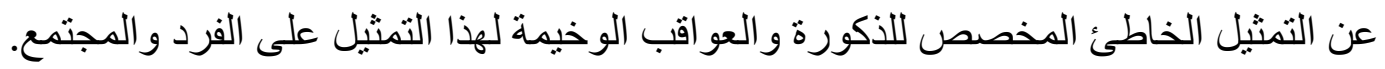

الكلماث الدالة: الرجولة، جوديث بتلر، جوزيف برودهوم ، الأداء الجندري ، الإعلان، السيميائية، بيريل اسنرجل. 